unfinished budget bills still being debated.

Advocates said that his speech marked a significant turning point. "This is the first time he's signalled that he's going to champion global HIV in this way," says Jennifer Cohn, an assistant professor of infectious diseases at the University of Pennsylvania in Philadelphia, and a policy adviser in Nairobi for Médecins Sans Frontières (MSF; also known as Doctors Without Borders). "Whether or not this gets translated into the president's 2013 budget request, or what Congress chooses to protect during the 2012 budget negotiations - that's what I'm waiting to hear."

Even if the United States manages to expand treatment for HIV/AIDS, research and development aimed at poor countries is suffering. Moran points out that of the $\$ 67.5$ million cut from HIV/AIDS research spending in 2010, $\$ 32$ million was due to cuts by the US National Institutes of Health, and a further \$17 million was cut by the UK Department for International Development (see 'Fighting a killer'). Other neglected diseases are seeing similar reductions in research funding (see go.nature.com/sgv7oj).

"A lot of this reflects the financial crisis, that's undoubted," Moran adds. "But with HIV, some of it also reflects a shift from the more costly late-stage vaccine and microbicide trials that haven't worked. We are moving back to basic research, which is cheaper."

The cutbacks coincide with encouraging results on HIV/AIDS treatment. One study published in August found that early treatment of those infected greatly decreases sexual transmission to their uninfected partners, (M. S. Cohen et al. N. Engl. J. Med. 365, 493-505; 2011). Other recent work suggests that ART, although costly, will pay for itself and more by increasing labour productivity, reducing the need for orphan care and deferring

\title{
FIGHTING A KILLER
}

Funding for research and development (R\&D) of HIV/AIDS products targeted at developing countries fell last year, whereas treatment with antiretroviral therapies has grown rapidly over the past decade.

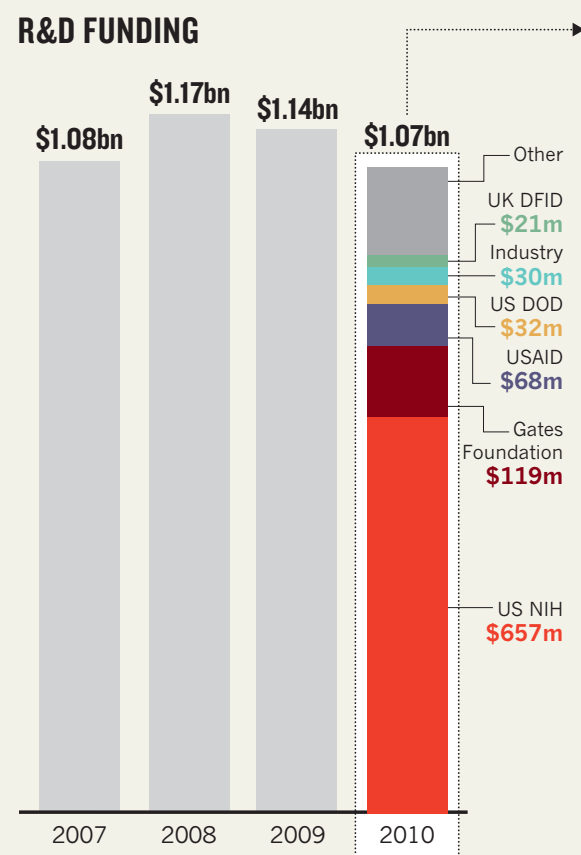

$\rightarrow$ RESEARCH

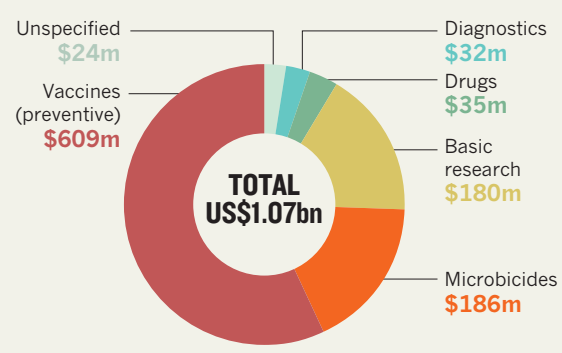

ANTIRETROVIRAL THERAPY

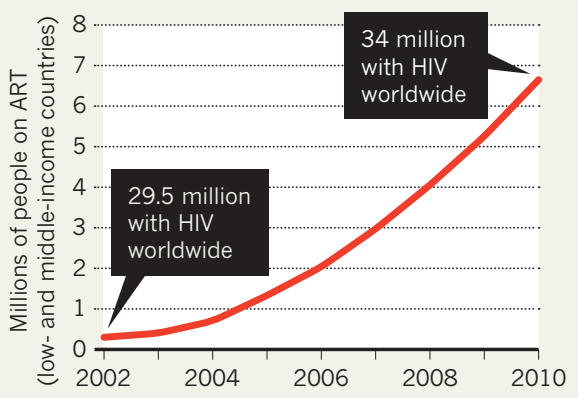

Figures are adjusted for inflation and reported in 2007 US dollars. ART, antiretroviral therapy; DFID, Department for International Development; DOD, Department of Defense; NIH, National Institutes of Health; USAID, US Agency for International Development.

medical treatment costs (S. Resch et al. PLoS ONE 6, e25310; 2011). "Not only is [treatment] the right thing to do, it's also the smart thing to do," says Sharonann Lynch, an HIV policy adviser with MSF in New York.

But the 'treatment equals prevention' equation invoked by Obama is not selling in all quarters. Roger Bate, a health economist and HIV expert at the American Enterprise Institute, a think tank in Washington DC, says that he is not yet persuaded by the studies suggesting that treatment prevents transmission. "There is a lot of effort out there to ignore noise in those studies," he says.

He adds that, even if treatment does prevent transmission, the commitment to treat infected people for their lifetimes quickly becomes an enormous financial outlay in future years. "Is it sustainable to treat even more people under current budgets?" he asks. "I don't think it is."

\section{Nano rules fall foul of data gap}

\section{Incomplete nanotoxicology research is hampering efforts to introduce regulation.}

\section{BY EUGENIE SAMUEL REICH}

$\mathrm{T}$ The science of the very small will lurk in many a Christmas gift this year. Nanomaterials add strength to golf clubs, odour resistance to socks and ultraviolet protection to cosmetics. But some of their properties could also pose health risks, and regulations covering their manufacture and use have failed to keep pace with the rush to market.

With sizes measured in mere billionths of a metre, nanomaterials have very high surface area relative to their mass, and this could alter their toxicity compared with the same material in bulk. Yet many nanomaterials are not regulated separately - in part because the high-quality nanotoxicity research needed for regulation is lacking, as an assessment presented at last week's Materials Research Society meeting in Boston, Massachusetts, made clear.

Groups representing food manufacturers had asked Cantox Health Sciences International, a consultancy in Mississauga, Canada, to review the literature for studies that could shed light on the effects of consuming nanoparticles from food packaging, in which they may be used to improve strength or even detect spoilage.

Cantox sampled 30 papers describing studies in which nanoparticles were fed to animals or applied in vitro to cells of the gastrointestinal tract. Of 21 animal studies, the Cantox researchers found that 15 failed to attain the highest grade on the Klimisch test, a qualitycontrol criterion that assesses whether basic data, such as the number or gender of animals used, have been reported. "Some didn't give the dosage. This is a fairly important aspect," says Jeffrey Card, a toxicologist at Cantox who led the study.

The underlying materials science was equally spotty. Of 10 parameters that Cantox concluded should be reported in a nanotoxicity 
study, such as particle size, shape and surface chemistry, more than half were missing from 14 of the animal studies ${ }^{1}$.

Yongping Bao of the University of East Anglia in Norwich, UK, an author on one of the studies ${ }^{2}$ given low marks by Cantox, points out that some of the missing data appear in other papers by his group. But he believes that the review highlights the need for government regulatory agencies to establish agreed standards for this sort of research. "Anyone can set his or her own criteria to review nanotoxicity literature, so a gold standard is urgently needed," he says. Nanotoxicity studies arguably require additional standards, because nanoparticles can vary within a batch much more widely than do bulk chemicals, for example.

Altaf Carim, assistant director of nanotechnology at the White House Office of Science and Technology Policy, says that the US National Nanotechnology Initiative's Environmental, Health, and Safety Research Strategy ${ }^{3}$, unveiled in October, will develop a set of standards that should help researchers and agencies to plug that gap. "We are certainly hoping the broader community is going to make use of it," Carim says.

Nanotoxicologists have also lacked standard reference materials for defining nanoparticles. The US National Institute of Standards and Technology has produced references for gold and polystyrene nanoparticles, but has yet to issue similar samples of other nanomaterials.

Later this month, however, the institute will release its first batch of standard reference carbon nanotubes - the result of three years' work, according to Kalman Migler, who is overseeing the project. Researchers will be able to buy vials of the nanotubes to calibrate their measurement equipment and assess levels of common contaminants in their samples. The reference nanotubes, the first ever provided by a national standards agency, should help nanotoxicologists to pinpoint whether any observed adverse reactions are the result of nanoparticles rather than impurities, for example.

Yet the latest nanotechnology decree from Europe perhaps shows how far regulation efforts still have to go. On 18 October, the European Commission finally adopted a definition of a nanomaterial: one in which half or more of the particles in a sample have one dimension that measures between 1 and 100 nanometres ${ }^{4}$. The definition had been requested by the European Parliament in April 2009.

1. Card, J. W., Jonaitis, T. S., Tafazoli, S. \& Magnuson, B. A. Crit. Rev. Toxicol. 41, 20-49 (2011).

2. Zhang, J.-S., Gao, X.-Y., Zhang, L.-D. \& Bao, Y.-P. BioFactors 15, 27-38 (2001).

3. NNI Environmental, Health, and Safety Research Strategy (US Natl Sci. Technol. Council, 2011); available at http://go.nature.com/8hkuv3

4. Potočnik, J. Official J. EU L275/38-L275/40 (2011).

\section{Novartis to shut brain research facility}

\section{Drug giant redirects psychiatric efforts to genetics.}

\section{BY ALISON ABBOTT}

$\mathrm{N}$ ovartis has joined other pharmaceutical companies in abandoning traditional drug-discovery programmes that pursue treatments for brain disorders.

Nature has learned that the company is closing its neuroscience facility in Basel, Switzerland, where Novartis is headquartered.

It follows similar moves by GlaxoSmithKline and AstraZeneca, both based in the United Kingdom, which last year announced the closure of all their neuroscience research divisions globally. US-based companies Pfizer and Merck, as well as the French company Sanofi, have also pulled back on research into brain disorders. Rather than abandon neuroscience, however, Novartis says it will launch new programmes to study the genetics of psychiatric and cognitive disorders, in the hope of identifying new treatment strategies.

Developing drugs for brain disorders has become a high-risk activity, with most candidates failing after years of expensive clinical trials. The market is already flooded with cheap, generic antidepressants, antipsychotics and other drugs that act on known targets in the brain, mostly neurotransmitter receptors (see 'Mental-health drug sales'). This has forced companies to look for radically new drug targets, but the search is proving difficult because little is known about the biology of the brain and its disorders.

"Standard approaches to developing drugs for mental health have not reaped significant benefit in the past two decades," says Ken Kaitin, director of the Tufts Center for the Study of Drug Development in Boston, Massachusetts. "But it is a dilemma for the companies because there is a large and growing market for these products." Mental disorders impose the largest disease burden worldwide (see Nature

\section{MENTAL-HEALTH DRUG SALES}

Treatments for brain disorders represented a huge market for the pharmaceutical industry in 2010.

$\begin{array}{ll}\text { Antipsychotics } & \text { Antidepressants } \\ \mathbf{\$ 2 2} \text { bn } & \$ 20 \text { bn }\end{array}$

$\$ 22$ b $\$ 20$ bn
478, 15; 2011), and current treatments do not work particularly well for most patients.

The Basel neuroscience department has 80 staff, and five candidate drugs in the pipeline that act on the central nervous system (CNS). These drugs will continue to be developed, says geneticist Mark Fishman, president of research for the company's main research arm, the Novartis Institutes of BioMedical Research (NIBR). Novartis is negotiating with unions over the terms of the closure, which is likely to happen during 2012.

Fishman says that the NIBR will open a new research division to study the genetics of psychiatry and cognitive disorders at its site in Cambridge, Massachusetts, taking advantage "Developing of academic strength Developing in the area, including drugs for the brain has become highrisk, with most candidates failing." the Broad Institute, run jointly by Harvard University and the Massachusetts Institute of Technology, which has both major DNAsequencing capacity and a large group dedicated to psychiatric genetics. "Progress based on neurotransmitters has become small and incremental," Fishman told Nature. "Genetic analysis will provide a real scientific opportunity in psychiatric and cognitive disorders, even if new drugs only arrive in the distant future."

Recent population-based, genome-wide association studies have identified many different genetic variants that individually confer tiny increased risk of disease, but which may act together to substantially increase a person's susceptibility. A type of defect known as copy number variation, in which large chunks of DNA are gained or lost, may on its own cause a significant increase in risk for psychiatric disease. Scientists hope that understanding the

L 